\title{
EdWARD SRI. Men, Women, AND the Mystery of Love. Cincinnati: Servant, 2015, 159 PP.
}

Carlos Alberto Rosas Jiménez*

DOI: $10.5294 /$ pebi.2018.22.1.13

Men, Women, and the Mystery of Love es el libro escrito por Edward Sri, profesor del Augustine Institute de Denver, Colorado, publicado en el 2015 por la editorial Servant, en el cual toma las enseñanzas de la obra del papa Juan Pablo II titulada Amor y responsabilidad presentándolas como una guía práctica, sin ser un manual seco sobre ética sexual o un tratado abstracto sobre el amor, que ayuda a los lectores a comprender la visión de Juan Pablo II sobre las relaciones entre el hombre y la mujer, y las puedan aplicar en sus propias vidas.

Edward Sri es profesor de teología y Sagrada Escritura en el Augustine Institute en Denver, Master of
Arts de la Franciscan University, en Steubenville, Licenciado y Doctor en Teología Sagrada de la Universidad Pontificia de Santo Tomás de Aquino en Roma. Ha enseñado en el Benedictine College por nueve años y trabajó con Curtis Martin para lanzar FOCUS (Fellowship of Catholic University Students), que comenzó ahí en 1998. Es un reconocido orador católico, director de contenido de la serie Symbolon: The Catholic Faith Explained, y de Beloved: Finding Happiness in Marriage. El profesor Sri ha escrito varios libros como Into His Likeness (2017), The Bible Compass: A Catholic's Guide to Navigating the Scriptures (2009), entre otros.

* Universidad de La Sabana, (Colombia). carlosalbertorosasj@gmail.com 
El libro está dividido en 14 capítulos, cuyos títulos damos a continuación ${ }^{1}$ : 1. Las tres clases de amistad. 2. Más allá del impulso sexual. 3. Evitar atracciones fatales. 4. Sentido y sentimentalidad: el verdadero papel de las emociones. 5. La ley del don: entender los dos lados del amor. 6. ¿Amor y responsabilidad? Construir confianza, intimidad y un amor maduro. 7. Resentimiento hacia la castidad: la crisis actual. 8. La batalla por la pureza. 9 . Inspirar amor: un volver a la modestia. 10. Hombres, mujeres y ternura. 11. Cómo la contracepción daña el amor. 12. Los fundamentos de la Teología del Cuerpo. 13. ¿Solteros(as)? Entrenarse para el matrimonio ahora. 14. Preparando su corazón para su esposo(a). De manera muy clara, el profesor Sri logra dar los elementos claves de cada uno de estos temas, para lo cual cita al papa Juan Pablo II y da sus propias apreciaciones y adecuados ejemplos. Al final de cada capítulo se anotan los apartes del libro Amor y responsabilidad que corresponden a la temática tratada y se registran algunos puntos con preguntas muy pertinentes para la discusión y reflexión, que puede ser personal o grupal. A continuación sintetizamos los elementos que nos han parecido más relevantes del libro.

1. El utilitarismo: la visión utilitaria de la vida afecta las formas como nos relacionamos con los demás, pues su principal objetivo es conseguir el propio beneficio o el propio placer, olvidándose de lo que pueda pensar, sentir o hacer la otra persona. Por tanto, la toma de decisiones en la vida se hace en busca de cumplir principalmente este objetivo. Bajo esta visión de la vida, en lugar de amar a una persona, se le utiliza,

1 Las traducciones son hechas por el autor de esta reseña. se le usa, en lugar de construir una relación basada en la búsqueda de un bien común para los dos.

2. El impulso sexual: esta es la materia prima sobre la cual surgen los actos de amor; por tanto, no es malo en sí mismo, pues está orientado hacia otra persona y provee el marco necesario para que se desarrolle el auténtico amor. Pero no puede ser equiparado con este, pues tal sentimiento involucra mucho más que las reacciones espontáneas, sensuales o emocionales que son producidas por el impulso sexual. El auténtico amor requiere de actos de la voluntad dirigidos hacia el bien de la otra persona; y dado que las personas no son esclavas ni de sus pasiones ni de sus deseos, el impulso sexual es más que un instinto animal y puede ser controlado, pues a diferencia de los animales, la persona humana es responsable de sus actos, incluida la respuesta que da a su impulso sexual.

3. Emociones vs. verdad: el profesor Sri dice que un peligro de hacer de las emociones una medida para el amor es que nuestros sentimientos pueden engañarnos. En efecto, el papa Juan Pablo II dice que los sentimientos en sí mismos son ciegos, porque no tienen que ver con el conocimiento de la verdad sobre la otra persona; por tanto, nuestros sentimientos solos no son una buena guía para nuestras relaciones. Muchos hombres y mujeres persisten en relaciones que en el fondo saben que no son buenas, notan ciertas faltas en la otra persona, los problemas salen a la luz, la ansiedad y la inseguridad afloran, ven muchas banderas rojas pero no hacen nada para terminar la relación, se justifican demasiado. Lo que sucede es que cuando se está emocionalmente muy ligado a alguien, se hace caso omiso de los problemas y se excusa rápidamente a la otra persona. Sin embargo, 
esta tendencia de dejarse llevar por las emociones es característica del amor sentimental, que evade la pregunta por la verdad, se exagera el valor de la otra persona quitándole el valor a sus faltas e ignorando los problemas reales que existen en la relación. Por esta razón hay que tener los ojos bien abiertos, sin idealizar a la otra persona y no dejarse alejar de la realidad.

4. Don y responsabilidad: en el amor de los que están comprometidos hay un gran misterio de reciprocidad en el dar y el recibir de cada uno. El aceptar a la otra persona como un don que se puede atesorar y cuidar implica también responsabilidad por el otro, justamente porque se ve como un don y no como un objeto del que puede sacar provecho o placer.

5. Castidad: es la virtud que libera el amor de las actitudes utilitarias. Tendemos a pensar en el amor solamente en su aspecto subjetivo; sin embargo, un amor que dure en el tiempo va más allá, está basado en la virtud, en un compromiso con el bien de la otra persona, en un darse mutuamente el uno al otro, en otras palabras, en el aspecto objetivo del amor. La castidad protege el amor de caer en el egoísmo, el utilitarismo, y permite amar desinteresadamente sin verse afectado por las poderosas emociones o el deleite sensual que pueda recibir del amado.

6. Ternura: la esencia de la ternura se encuentra en la tendencia de hacer propios los sentimientos y estados mentales de la otra persona. Pero no es suficiente tener consciencia de lo que sucede en el interior de la otra persona, pues uno también quiere comunicar el sentido de cercanía a su amado, y eso se logra de diferentes maneras en una relación. Pero estas expresiones pueden darse prematuramente antes de que los elementos del amor hayan madurado, como la amistad, el darse al otro y la responsabilidad.

7. La teología del cuerpo incluye varios elementos dentro de los cuales podemos destacar aquí la ley del don, que quiere decir que las personas humanas están hechas para un amor que se dona (self-giving love), no para darse amor (self-getting love), y alcanzan su plenitud cuando se dan a sí mismas en el servicio a los demás. Hombres y mujeres están hechos para vivir en comunión personal íntima del amor que se dona, siendo espejo de la vida interna de la Trinidad.

8. Entrenamiento para el matrimonio: el profesor Sri insiste en que el matrimonio trae muchos retos y exigencias que conllevan una actitud que implica un ceder a los propios gustos y una gran capacidad de donación de sí mismo. No obstante, si esas actitudes no se forjan en la soltería, es difícil que se pueda vivir con las exigencias que el matrimonio envuelve. Por esta razón, en la soltería hay docenas de oportunidades para practicar el servicio a los demás. Si la persona está llamada al matrimonio pero no ha encontrado su pareja, es importante que saque provecho de ese tiempo como una oportunidad de especial formación. Es importante confiar en la providencia divina que nos señala que ese tiempo hace parte del plan de Dios, quien puede estar forjando muchas cosas en el alma de esa persona o incluso de su pareja.

9. Preparar el corazón: en realidad nada podrá preparar completamente a las personas para el matrimonio; sin embargo, es posible preparar de alguna manera el corazón para ese momento. Primero, se debe volver el corazón hacia afuera, enfocado hacia los demás, educándose en un amor desinteresado por los demás. 
Segundo, preparar el corazón para una mayor entrega. Tercero, abrir más el corazón al amado. Cuarto, volver más el corazón hacia Dios a través de la oración.

Aunque el libro reseñado carece de una conclusión general, el profesor Sri logra exponer de manera muy clara, contundente y a la vez sencilla los contenidos del libro Amor y responsabilidad del papa Juan Pablo II. Es por eso que recomendamos vivamente el uso de este libro como una herramienta muy valiosa para la formación de jóvenes, adultos, solteros y casados en la vivencia del amor de pareja a la luz de la fe católica. El libro, de fácil y fluida lectura, podría ser traducido al español y convertirse en una herramienta pastoral de gran alcance, pues no utiliza términos muy filosóficos o teológicos que puedan desalentar la lectura. Por el estilo de redacción del libro, se pueden preparar conferencias sobre cada uno de los capítulos y prestarse para una amplia difusión, por lo cual invitamos a la traducción del mismo en varias lenguas. 